\title{
Giant cell arteritis of coronary arteries causing myocardial infarction
}

\author{
J F MARTIN, C KITTAS, D R TRIGER \\ From the Department of Medicine, University of Sheffield, Floor M, Hallamshire Hospital, Sheffield
}

SUMMARY A case of giant cell arteritis involving the coronary arteries and causing thrombosis and myocardial infarction is described. IgM deposits in the affected arteries were demonstrated by an immunoperoxidase technique.

Death from giant cell arteritis alone is rare and is mainly the result of ruptured aorta (Östberg, 1973; Klein et al., 1975). Arteritic involvement of the coronary arteries is even more rare, there being 6 published cases (Morrison and Abitol, 1955; Ainsworth et al., 1961; Östberg, 1973; Klein et al., 1975). Myocardial infarction has been claimed in 2 cases (Morrison and Abitol, 1955; Ainsworth et al., 1961), but the reports give no evidence of a causal link between the arteritis and myocardial infarction. We describe a case of giant cell arteritis with histologically proven involvement of the coronary arteries causing thrombosis, myocardial infarction, and death.

\section{Case report}

A 77-year-old housewife complained of central chest pain, radiating to her left arm and neck, initiated by exertion and lasting 2 hours. For 9 months previously she had malaise and weight loss. For 3 months she had suffered severe burning headaches and jaw claudication. On examination she was pale and had very tender temporal arteries. Her eyes were normal. A clinical diagnosis of giant cell arteritis was made. ESR was $85 \mathrm{~mm} / \mathrm{h}, \mathrm{Hb}$ $11 \cdot 1 \mathrm{~g} / 100 \mathrm{ml}$. Electrocardiogram was normal. Treatment with prednisolone $60 \mathrm{mg}$ daily was begun and the next day she felt better. On the third day after admission she again complained of severe chest pain and collapsed. Ventricular fibrillation was converted to sinus rhythm by DC shock. Electrocardiogram showed an anterior myocardial infarction. Intravenous lignocaine controlled ventricular ectopic beats, but she died 6 hours later after an episode of asystole.

Necropsy showed the aorta and coronary vessels to be free from atheroma. The anterior descending branch of the left coronary artery was completely occluded by a thrombus $3.6 \mathrm{~cm}$ from the ostia. A large area of the anterior and anteroseptal walls of the left ventricle was infarcted. Histological examination showed changes of giant cell arteritis, in the cerebral, coronary, and temporal arteries; the latter being more severely damaged. Sections taken from the anterior descending branch of the left coronary artery showed occlusion of the lumen by a thrombus superimposed on active arteritic changes (Fig. 1). Sections stained by the immunoperoxidase method (Heyderman and Munro-Neville, 1977) for immunoglobulins, showed strong cytoplasmic and weaker granular extracellular staining for IgM adjacent to the elastic lamina (Fig. 2). The cells positive for IgM were plasma cells and a few macrophages. There was no histological involvement of the aorta.

\section{Discussion}

Angina in a patient with temporal giant cell arteritis is most likely to be caused by unrelated atheromatous changes in the coronary tree. However, involvement of the latter by giant cell arteritis should be borne in mind in view of its potential reversibility with prednisolone. Our patient died of coronary artery occlusion after receiving an adequate dose of prednisolone for 3 days; 3 of the reported cases of aortic rupture also died while receiving adequate doses of prednisolone and after symptomatic improvement (Klein et al., 1975). We believe that these results do not reflect the irreversibility of the arteritic changes but underline the necessity of early diagnosis and treatment before the establishment of lesions such as thrombosis of the coronary arteries or weakness of the aortic wall, 

coronary artery showing two giant cells in the bottom right-hand corner, and in the top left-hand vessel wall $(\times 100)$.
Fig. 1 Section through the corner thrombus is adherent to the

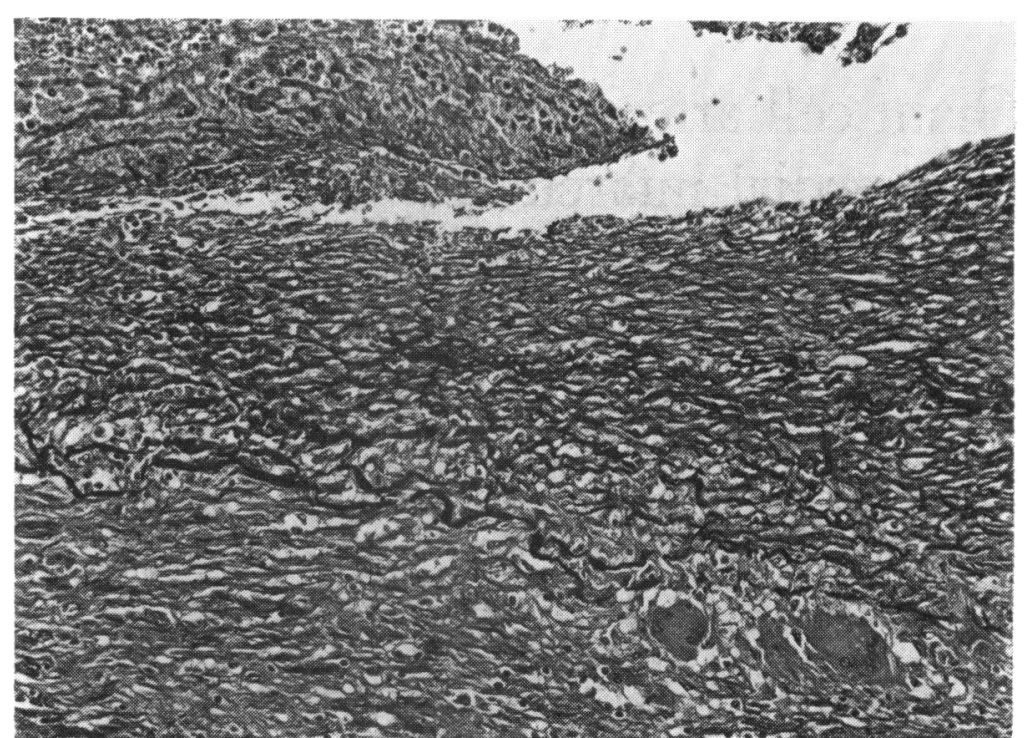

leading to myocardial infarction and ruptured aorta, respectively.

Immunoglobulins have been found using immunofluorescence, in temporal arteries affected by giant cell arteritis (Liang et al., 1974); it has also been suggested that the demonstration of IgM should be the criterion of diagnosis in temporal arteritis (Bonnetblanc et al., 1978). We have here shown IgM in both the temporal and the coronary arteries using an immunoperoxidase method. In the diagnosis of giant-cell arteritis this technique may be of greater value than immunofluorescence as it can be applied to formalin-fixed, paraffinembedded material.
Fig. 2 Section through the coronary artery showing chronic inflammatory infiltrate. A giant cell $(G)$ is shown. The arrows indicate plasma cells with strong cytoplasmic immunoperoxidase staining for IgM. Weak extracellular IgM deposits are also present $(\times 400)$.

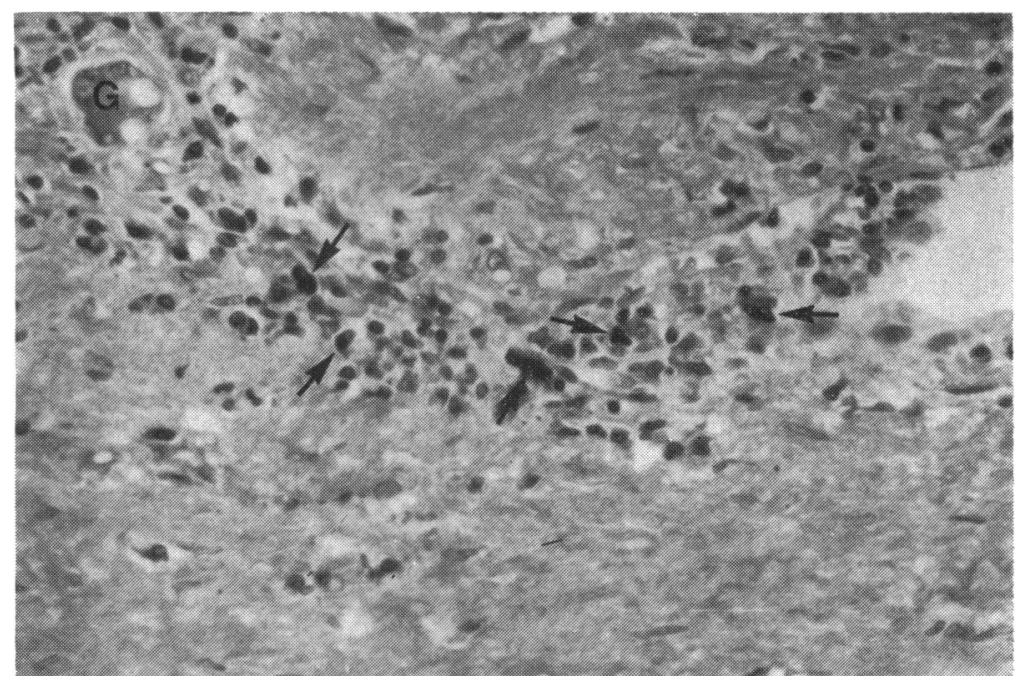




\section{References}

Ainsworth, R. W., Gresham, G. A., and Balmforth, G. V. (1961). Pathological changes in temporal arteries removed from unselected cadavers. Fournal of Clinical Pathology, 14, 115-119.

Bonnetblanc, J. M., Adenis, J. P., Queroi, M., and Rammaert, B. (1978). Immunofluorescence in temporal arteritis. New England fournal of Medicine, 298, 458.

Heyderman, E., and Munro-Neville, A. (1977). A shorter immunoperoxidase technique for the demonstration of carcinoembryonic antigen and other cell products. fournal of Clinical Pathology, 30, 138-140.

Klein, R. G., Hunder, G. G., Stanson, A. W., and Sheps, S. G. (1975). Large artery involvement in giant cell (temporal) arteritis. Annals of Internal Medicine, 83, 806812.
Liang, G. C., Simkin, P. A., and Mannik, M. (1974). Immunoglobulins in temporal arteries: an immunofluorescent study. Annals of Internal Medicine, 81, 19-24.

Morrison, A. N., and Abitol, M. (1955). Granulomatous arteritis with myocardial infarction: a case report with autopsy findings. Annals of Internal Medicine, 42, 691-700.

Östberg, G. (1973). On arteritis with special reference to polymyalgia arteritica. Acta Pathologica et Microbiologica Scandinavica, Suppl. 237, 1-59.

Requests for reprints to Dr J. F. Martin, Department of Medicine, University of Sheffield, Floor M, Hallamshire Hospital, Sheffield S10 2JF. 